Journal of The Faculty of Science and Technology (JFST)

http://journal.oiu.edu.sd/index.php/JFST

https://doi.org/10.52981/jfst.vi7.954

ISSN: 1858 - 6007

مجلة العلوم و التقانة ـ جامعة أم درمان الإسلامية ـ وزارة التعليم العالي و البحث العلمي ـ السودان

Research article

JFST Issue No. 7 (2020) 56 - 68

\title{
Neyo: A katabatic dry wind
}

\author{
Hassan Addom \\ Sudanese Meteorological Society Khartoum Sudan \\ Ammar Gaber
}

Sudanese Meteorological Society and Sudan Meteorological Authority. Khartoum Sudan

Abulgasim Idris

Sudan Meteorological Authority Khartoum Sudan

\begin{abstract}
The objective of this study is to explain how the Neyo wind stream develops and how it can damage crops and endanger people's lives in the Darfur Region of Sudan. Due to lack of official meteorological observations, the data was retrieved from NOAA Air Resources Laboratory (ARL) used by the Hybrid Single Particle Lagrangian Integrated Trajectory Model (HYSPLIT). Three scenarios for katabatic flow were formulated. Forces acting on air parcels were calculated for different slope angles. HYSPLIT vertical soundings revealed a reservoir of dry air over the area. Air parcels moving down slope allow dry air to flow across the thermal inversion layer. Due to the moisture deficit between the down flowing air and the humid grass surface, the leaves get dehydrated.
\end{abstract}

\section{Keywords:}

Darfur; nocturnal radiation; katabatic flow; dehydration

\section{Introduction}

Deserts are characterized by low humidity, clear skies and large diurnal variation in temperature. The large area of the Sahara Desert can modify air masses and give them desert characteristics. The north-western areas of Sudan are part of the Sahara. Residents of the rural areas of northern and western Darfur frequently report cold wind breeze that damages their crops. They call it Neyo. The leaves of green grass and trees fall to the ground as the Neyo stream passes over them. Unprotected people and animals might be 
killed. The phenomenon extends for few hundred meters and has a lifetime of few minutes. It occurs on hill sides in the early morning hours. Most of the cases were reported in the months of December and January. Typical areas of Neyo occurrence include Geneina, Kutum, Kass and adjoining areas.

The Neyo is restricted by space and time. Regarding space, it develops in the mountainous desert areas. Regarding time, its preferred time is the early morning hours of the long winter nights. Natives in northern and western Darfur describe the Neyo as a cold air breeze that occurs on hill sides, (Ishaq, 2011). Actual observations do not support this assumption for two reasons. Firstly, the Neyo stream is confined to a narrow strip down the valley. A descending air mass will get compressed and will warm up adiabatically. It is therefore must be warmer than the environmental air mass. Secondly, the temperature gradient between the Neyo air mass and the surrounding air will lead to pressure differences and that will lead to a strong turbulent flow. Actual observations describe the Neyo as a gentle breeze. Opposing these postulates, we assume that the Neyo is a dry wind. This assumption leads to many questions. If a Neyo is a dry wind, why does it occur at specific locations and at specific times? What makes this phenomenon occur at hill slopes and in the early morning hours?

Available literature links katabatic winds to nocturnal radiation, Helmis and Papadopoulos (1996), Haiden and Whiteman (2004) and Vihma et al (2011). The famous Santa Ana winds that blow into the Los Angeles area are typical valley winds. Their main characteristics include the extremely low relative humidity and the strong wind speed, Hughes and Hall (2010).

Katabatic flows are described by Prandtl model (Giometto 2016). Air on a hill side is subject to gravity, buoyancy and drag forces. The balance is between the gravitational force and the drag force. The latter is related to momentum diffusion normal to the slope surface. The air in contact with the soil is cooler and denser than the air away from the soil. The cooler air moves downwards. Drag force starts to retard this motion. Downslope flows get compressed, and warm up. The temperature difference that leads to the start of the flow at the beginning vanishes. Eventually the downslope stream stops. It takes some time for nocturnal radiation to re-build a new buoyancy force. A harmonic oscillatory motion occurs. McNider (1982) found that the period of oscillation depends on the angle of the slope of the surface. This means that only specific locations can generate downslope flows. This flow depends also on the rate of cooling of the air on the surface. Clear skies of the long nights of the desert avail ideal conditions for nocturnal radiation. The flow type can 
develop forces that affect the rate of drainage of air. This affects the time needed to build thermal inversions.

The objective of this study is to explain how the Neyo wind stream develops and how it can damage crops and endanger people's lives.

The study profile shows that the theory and method are stated on section 2 . The results are given in detail in section 3. Here we explained the outcome of the interview made by local people. On this section the source of the dry air was described, the mechanism of down slope flow and the impact of dry air on wet surfaces were explained. The conclusion was given on section 4 followed by the list of references.

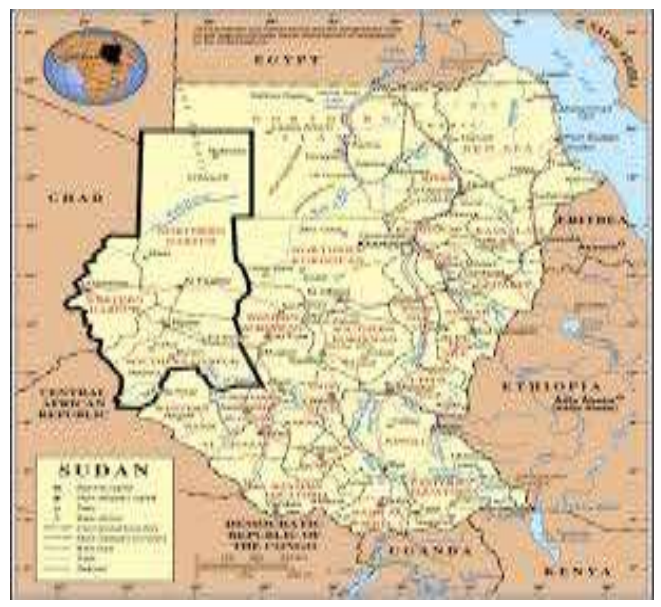

Figure 1: Map of the Darfur Region of Sudan.

\section{Method:}

Our approach is to build an image of the Neyo stream based on the generation of katabatic wind along hill sides. This katabatic wind will drain the pool of dry air hanging at few hundred metres above the ground level. The effect of the dry air on underlying grass will be investigated.

The spatial and the temporal scales of the Neyo are too small to be captured by synoptic weather networks. Available meteorological products cannot

reflect this phenomenon which extends for few hundred meters and for few minutes of time. In order to link its evolution to known meteorological conditions, 20 people from the 
study area were interviewed about the Neyo. The questions were designed to give concise description of the phenomenon: the places and times of occurrence, its duration, frequencies and impact.

The motion of an air parcel on a hillside is a katabatic wind controlled by gravitational and drag forces. Rao and Snodgrass (1981) described such wind flow as:

$$
\frac{\partial u}{\partial t}=\frac{g d \sin \beta}{\Theta}+K_{m} \frac{\partial^{2} u}{\partial n^{2}}
$$

Where $u$ is the average downslope wind velocity, $t$ is time, $g$ is the acceleration due to gravity, $d$ is the temperature deficit between the surface and inversion layer, $\beta$ is the slope angle of the valley, $\Theta$ is the ambient potential temperature, $K_{m}$ is the turbulent diffusivity of momentum $\left(m^{2} s^{-1}\right.$ ) and $n$ is the distance measured normal to surface of slope (in $m$ ). The first term on the right-hand side of equation (1) depends on the slope of the hill, the strength of the inversion layer and the potential temperature of the air. The potential temperature was calculated from equation (2):

$$
\Theta=T\left(p_{o} / p\right)^{\kappa}
$$

where $\Theta$ is the potential temperature, $\mathrm{T}$ is the temperature, and $\kappa$ is the ratio of the gas constant and it is assumed to be 2/7 (Salby, 1992). Potential temperature was estimated as $300 \mathrm{~K}$ from table 1 . Acceleration due to gravity was taken as $10 \mathrm{~ms}^{-2}$

The second term on the right-hand side of equation (1) depends on the drag coefficient and the shape of the flow. Turbulent diffusivity of momentum was

considered equal to $0.06 \mathrm{~m}^{2} \mathrm{~s}^{-1}$, after Helmis and Papadopoulos (1996). The drag force was calculated for each scenario.

The forces acting on an air parcel on the side of a slope terrain for scenarios I and II were calculated for different slope angles, from $01^{\circ}$ to $30^{\circ}$. For a fixed potential temperature of $300 \mathrm{~K}$ and fixed turbulent diffusivity of momentum of $0.06 \mathrm{~m}^{2} \mathrm{~s}^{-1}$, the corresponding inversion temperatures were found for zero acceleration along the hill side.

Vertical profiles of temperature and humidity were downloaded from NOAA's Air Resources Laboratory (ARL) to give an image of vertical structure of the tropospheric air mass over the study area. The basic information was extracted from ARL soundings at 
arbitrary locations for arbitrarily chosen days. All soundings represent the 00UTC time corresponding to 0200LT (4 hours before sunrise). ARL uses the Hybrid Single Particle Lagrangian Integrated Trajectory Model (HYSPLIT). It displays meteorological data fields interpolated to a regular latitude-longitude grid.

Three scenarios of the vertical profile of wind at hill slopes were formulated to express the drag force. We assume that the thickness of the flow extends for few metres. The first scenario (Sc I) suggests that the speed of down slope wind increases with height to a specific height (3 metres) and then decreases. The second scenario (Sc II) suggests that the speed of the downslope wind increases with height up to 3 metres and then remains constant. The third scenario (Sc III) suggests that the speed increases steadily with height. Figures $2 \mathrm{a}, \mathrm{b}$ a+nd $\mathrm{c}$ show schematic diagrams of vertical profile of wind flow according to the three scenarios.

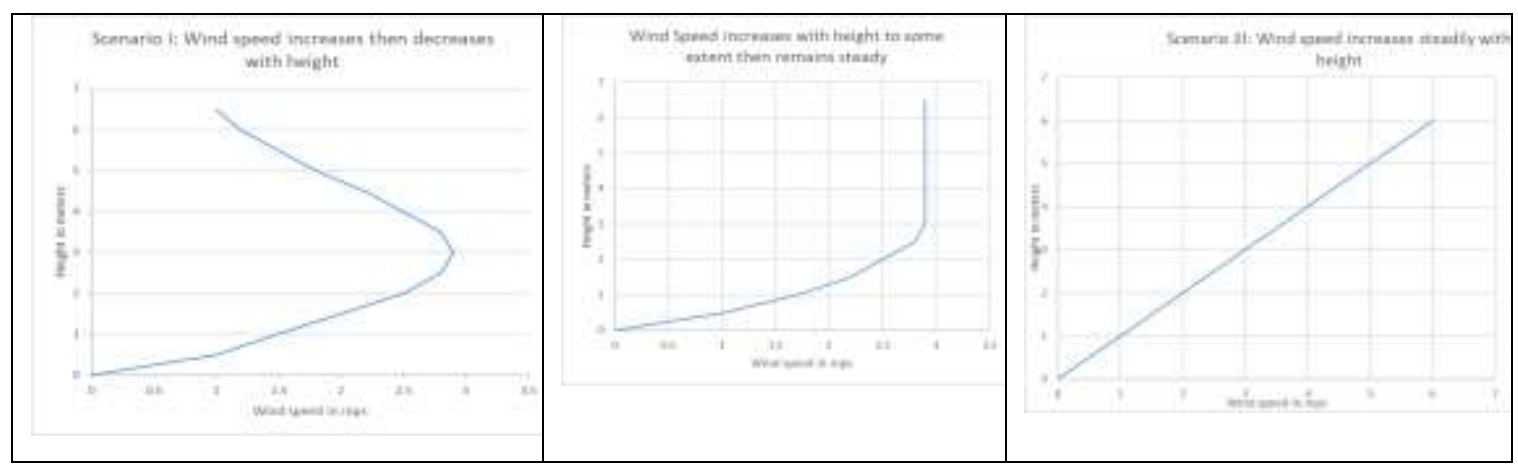

a: Wind increases then decreases.

b: Wind increases then remains constant c: Wind increases steadily

Figure 2: Wind profile with height according to three scenarios.

For scenario III, the drag force is zero and the air parcel is subject to gravity and buoyancy forces. These forces do not give the air parcel enough time to build temperature difference with the overlying air. Such a flow will not support the development of thermal inversions. 
Table 1

Basic information extracted from random NOAA ARL soundings for the study area.

\begin{tabular}{l|l}
\hline Parameter & Value \\
\hline Surface pressure & $900 \mathrm{hPa}$ \\
Pressure at inversion level & $800 \mathrm{hPa}$ \\
Saturation mixing ratio at the surface & $20 \mathrm{gm}$ \\
Actual mixing ratio above the inversion layer & $0.2 \mathrm{gm}$ \\
Surface air temperature & $12 \mathrm{C}$ \\
Temperature at the inversion layer & $17 \mathrm{C}$ \\
Average potential temperature below the inversion layer & $290 \mathrm{~K}$ \\
Potential temperature at the base of the inversion layer & $300 \mathrm{~K}$ \\
\hline
\end{tabular}

\section{Results and Discussion:}

A comprehensive description of the phenomenon showed that the phenomenon occurs at hillsides in the early morning hours. All interviewed people described the Neyo as a very cold wind that blows down slope of hills and valleys at a small speed. It is frequently observed in the cold months of December and January. The preferred period for the Neyo occurrence is the early morning, before sunrise. Its duration ranges between few minutes and half an hour. The impacts of the Neyo include the drying of green grass and trees. There were stories that some people were killed by the Neyo. The victims were either shepherds spending the nights away from home, or farmers walking to their farms before sunrise. The sound of falling leaves is an indication of imminent onset of a Neyo. However, this does not give a person enough time to avoid it. To avoid a Neyo, a person has to lie on the ground with his face downwards or has to run into a shelter. In case that a person is caught by a Neyo, he will be paralyzed and unable to walk.

\section{Source of Dry Air:}

It is important to find the source of this dry air. Although the Neyo phenomenon occurs in the desert, the source of the dry air is not the surface air mass. This ground surface air mass extends evenly over large areas without leading to Neyo properties. Figures 3 (a and b) show the soundings

retrieved from the NOAA Air Resources Laboratory (ARL). The line to the right shows the temperature profile and the one to the left shows water vapor mixing ratio. The vertical 
stratification of the temperature field is characterized by a thermal inversion from the ground surface to the $800 \mathrm{hPa}$ level accompanied by a moisture discontinuity. The dry air is located somewhere above the level of thermal inversion. The inversion is created by two physical processes. The first one is due to nocturnal radiation. The nocturnal radiation at the ground surface cools the surface air faster than it cools the overlying air. The second process is due to subsidence. The descending branch of the Hadley cell brings very dry air from higher levels, (Salby, 1992). The descending air remains hanged over the inversion layer creating a pool of very dry air. Thermal inversions keep this dry air at few hundred meters above the inversion layer.

We can say that the dry air is a result of:

1- The subsiding air of the Hadley cell brings air with little moisture content.

2- The thermal inversion prevents mixing between the dry air aloft and the less dry air underneath.

3- Lack of source of water vapor above the inversion layer.

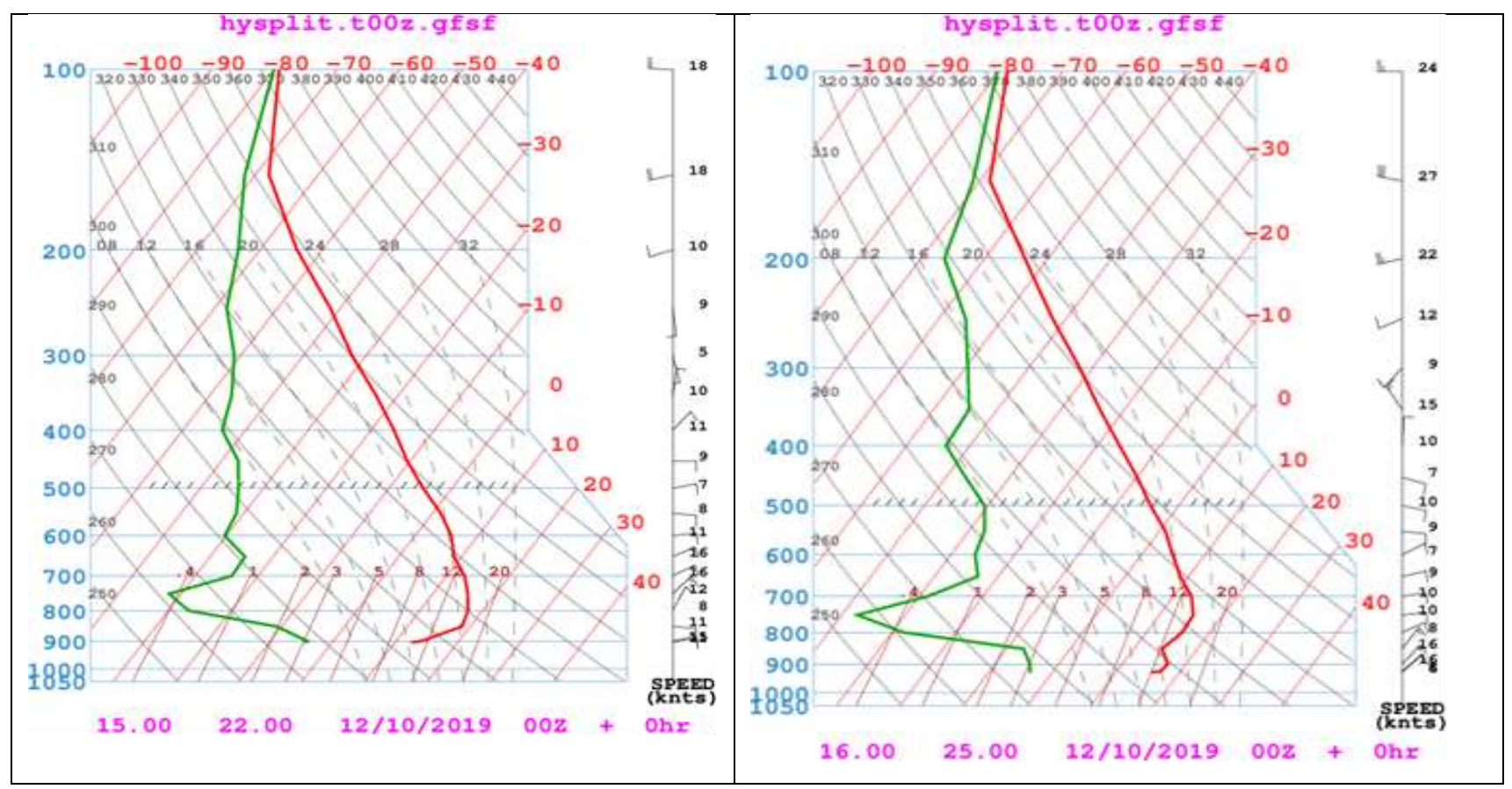

Figures 2: $\mathrm{a}$ and $\mathrm{b}$ show the vertical profile of temperature and dew point temperature as extracted from the NOAA Air Resources Laboratory on 10 December 2020 for the points $(15.00 \mathrm{~N}, 2200 \mathrm{E})$ and $(16.00 \mathrm{~N}, 25.00 \mathrm{E})$

\section{Down-slope Motion}

The information extracted from the interviews shows that the Neyo occurs on mountainous areas in the early morning period. Equation (1) gives a mathematical description for this 
motion. For a fixed potential temperature $(300 \mathrm{~K})$ and a fixed turbulent diffusivity of momentum $0.06 \mathrm{~m}^{2} \mathrm{~s}^{-1}$, (Helmis and Papadopoulos, 1996), the balanced forces (acceleration zero) acting on an air parcel on the hill side was calculated for different slope angles for scenarios I and II. The corresponding thermal inversion temperatures were plotted against a range of hill slope angles. The results for scenarios I and II are shown on figure 4.

Scenario III shows that the gravity forces exceed the drag force for all slope angles and for all thermal inversions. The downslope flow does not have

enough time to build up thermal inversions. This is not favorable for a Neyo formation. Forces were calculated for different slope angles and for different inversion temperatures. The forces acting on the air parcel are the net gravity/buoyancy force downwards and the opposing drag. Downward motion occurs when the gravity force exceeds the drag. Small slope angles do not produce enough downward force to exceed the drag force. Weak buoyancy forces fail to generate downward motion. With steeper terrains and strong thermal inversions, the gravity forces exceed the drag force and the air starts to flow downwards. The zero-acceleration lines for scenarios I and scenario II are shown on figure 4. Downward motion is expected to the right of the shown curves. Small inclination angles need larger thermal inversions to allow downward motion. For example, a slope of $30^{\circ}$ needs a thermal inversion of $10^{\circ} \mathrm{C}$ in case of scenario I and $25^{\circ} \mathrm{C}$ in case of scenario II. Such inversions do not exist.

Very steep terrains (slopes of $20^{\circ}$ or more) need small thermal inversions $\left(2^{\circ} \mathrm{C}-3^{\circ} \mathrm{C}\right)$ to start downward motion. Thermal inversions of $5^{\circ} \mathrm{C}-7^{\circ} \mathrm{C}$ are capable to generate downward flow at terrains with $10^{\circ}-15^{\circ}$ slopes.

As the air pours down the slope of a hill side, the drier air will flow downwards by continuity. A quite different air mass is now flowing over the surface. 


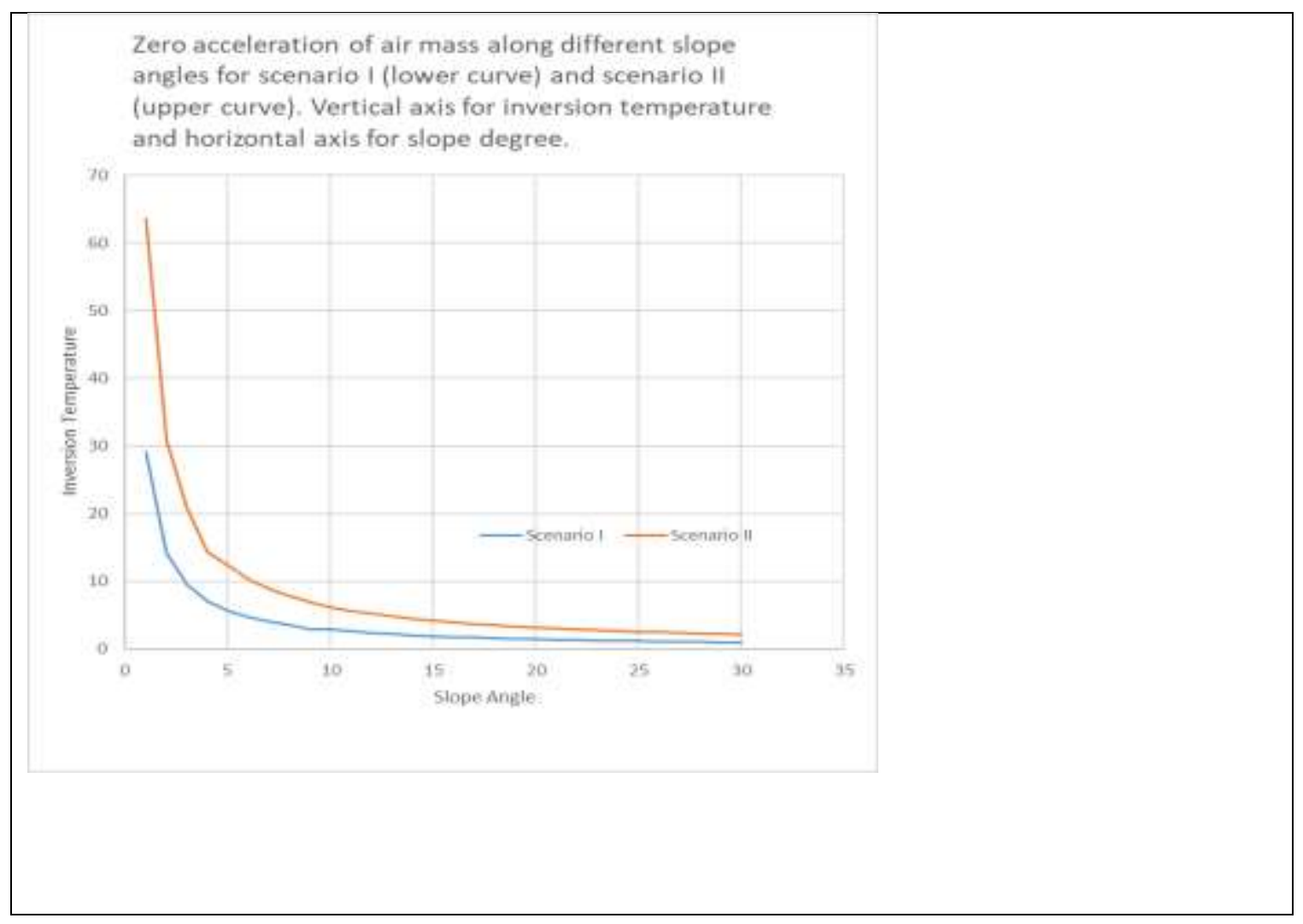

Figure 4: The zero-vertical acceleration of an air parcel for different slope angles and different thermal inversions according to scenarios I and II are shown.

\section{Effect of Dry Wind}

Exchange of water between the sources and air is governed by the Penman equation, (Sellers, 1992). The transfer of water from a surface to the air is given by the equation:

$L E=\beta\left(\frac{e_{s}\left(T_{s}\right)-e}{r_{a}}\right) \frac{\rho C_{p}}{\gamma}$

Where $E$ is the rate of evaporation mass in $\mathrm{kgm}^{-2} \mathrm{~s}^{-1}$

$L=$ Latent heat of vaporization

$\rho=$ The density of air in $\mathrm{kgm}^{-3}$

$C_{p}=$ heat capacity of air in $\mathrm{Jkg}^{-1} \mathrm{~K}^{-1}$

$r_{a}=$ momentum surface aerodynamic conductance in $\mathrm{ms}^{-1}$ 
$e_{s}=$ saturation vapor pressure in $P a$

$e=$ Actual vapor pressure in $P a$

$\gamma=$ Psychrometric constant in $\mathrm{PaK}^{-1}$

$\beta=$ Beta function is an index of moisture availability. It varies between 1 for wet soil and

0 for dry soil.

Evaporation is directly proportional to the difference in moisture content between the surface of the source and the air in contact with the moist surface. If all other parameters are considered constant at the small scale, then:

$E=C\left(e_{s}-e\right)$

$\mathrm{C}$ is the constant of proportionality

Assume that $E_{1}$ is the evaporation at the surface in a normal night, then

$$
E_{1}=C\left(e_{s}-e\right)=C\left(1-\frac{e}{e_{s}}\right) e_{s}
$$

$$
R H=\frac{e}{e_{s}} \times 100=\frac{q}{q_{s}} \times 100
$$

Where $q_{s}$ is the saturation specific humidity and $q$ is the specific humidity.

The mixing ratio at the ground level (table 1) was taken equal to $q_{s}=20 \mathrm{gm}$ at $20^{\circ} \mathrm{C}$.

Dry air pours down over the grass, evaporation rate will increase. The specific humidity of the new dry air was taken as $0.2 \mathrm{gm}$ as shown on table 1 . With saturation specific humidity kept at $20 \mathrm{gm}$, the relative humidity will be:

$$
R H=\frac{q}{q_{s}}=\frac{0.2}{20}=0.01
$$

Substituting in equation (5), we get:

$$
E_{2}=C(1-0.01) e_{s} \approx C e_{s}
$$

Dividing equation 8 by equation 5

$$
\frac{E_{2}}{E_{1}}=\frac{1}{1-\frac{e}{e_{s}}}
$$


This will lead to:

$$
E_{2}=\frac{100}{100-R H} E_{1}
$$

Here $R H$ is the relative humidity at the ground level.

This is the evaporation rate during the onset of the dry air. The moisture content of the descending air parcel remains the same as its temperature increases. This lowers its relative humidity. The relative humidity on the surface remains constant. Evaporation rate depends on the difference between the evaporating surface and the overlying air. The contact of the downflowing dry air with the green grass increases the deficit between relative humidity on the leaves surface and the overlying air. The ratio of the Neyo evaporation rates to the normal conditions were calculated and shown on the figure 5 below. As Neyo dry air flows over a wet grass with relative humidity of about $80 \%$, the evaporation rate becomes five times the evaporation rate before the onset of the Neyo air. With $90 \%$ relative humidity, the Neyo evaporation rate becomes 10 times the normal conditions. With such sudden loss of water, the leaves will dry instantaneously and fall to the ground.

The descending air will evaporate multiples of the surface air. At humid surfaces, with relative humidity approaching $80 \%$, the descending dry air can evaporate 5 times the rate of the ordinary conditions. 


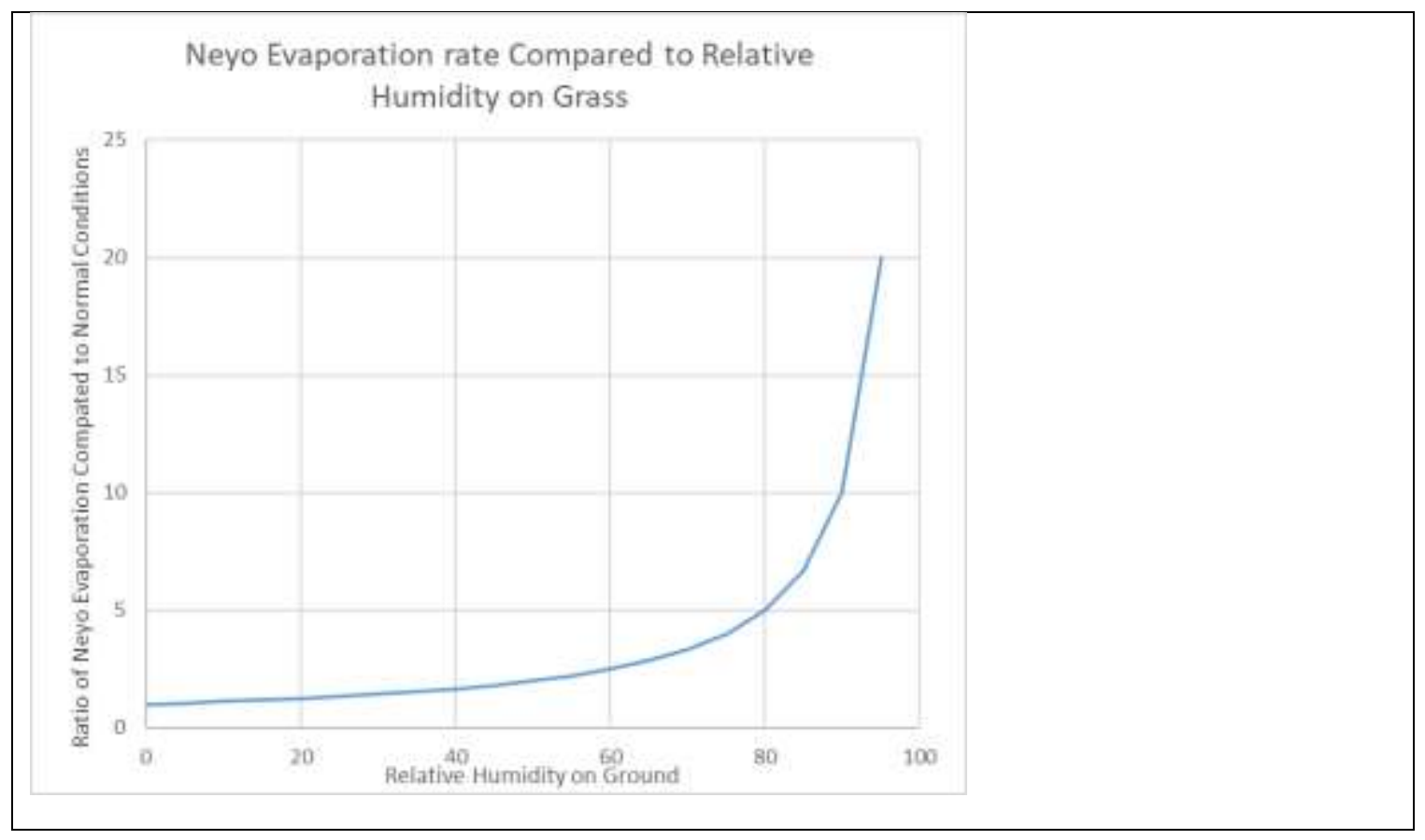

Figure 5: The ratio of evaporation rate during Neyo conditions to evaporation during normal conditions were plotted against all possible relative humidity values: from $00 \%$ to $95 \%$.

\section{Conclusion:}

The Neyo develops by the interaction of the terrain features and the atmospheric conditions on the boundary layer. A pool of dry air forms above the thermal inversions at about 800 hPa level. This dry air is a result of the descending branch of the Hadley cell and the nocturnal radiation in the clear sky winter nights. Sloping hill sides create downslope wind

stream due to buoyancy and gravity forces. Both flat and very steep terrains do not generate Neyo wind stream. On flat terrains gravity force is too weak to force downward motion. At very steep slopes the air flows downwards before a thermal inversion is built. Moderate slopes are more likely to fulfill Neyo conditions. The Neyo will not form unless a thermal inversion is closer to the hill tops. This depends on the synoptic weather conditions in the area. As airflows downward the hill side, very dry air from above the inversion layer will pour down. It becomes compressed and warmed. Its temperature increases and its relative humidity will drop further and further. The rate of extraction of moisture from the underlying surfaces increases. The study gives descriptive information of the phenomenon. A field study is highly recommended to build a realistic image of the Neyo. 


\section{References}

Giometto, M. G. 2016: Theoretical and numerical studies of atmospheric boundary layer flows over complex terrain. Thesis for Doctorate in Sciences, Ecole Polytechnique, Federale

\section{De Lausanne.}

Helmis, C. G. and 1996: Some aspects of the variation with time of katabatic flow Papadopoulos, over a simple slope. Roy. Met. Quart, J. Vol. 122, 595 K.H. 610.

Mimi Hughes M. 2010: Local and synoptic mechanisms causing Southern and A. Hall California's Santa Ana winds. Climate Dynamics; Vol 34, 6, pp $847-857$

Ishaq I. A.

2011: The Arabic origic of the Darfurian Arabic. Part 2. Page 475. Published by Khartoum New Book Centre.

McNider, R.T. 1982, A note on velocity fluctuations in drainage flows. J. Atmos., Sci., 39, 1658 - 1660

Salby, R.H. $\quad 1992$ Biophysical models of land surface processes. Edited by K. E. Trenberth in Climate System Modeling, Cambridge University Press

1992 The Atmosphere. Edited by K. E. Trenberth in Climate Sellers, P.J. System Modeling, Cambridge University Press 